\title{
Indikator yang Membedakan Gejala Psikotik dengan Pengalaman Spiritual dalam Perspektif Neurosains (Neuro-Anatomi)
}

\author{
${ }^{1}$ Priscilla E. Lumingkewas \\ ${ }^{2}$ Taufiq F. Pasiak \\ ${ }^{2}$ Shane. H. R. Ticoalu
}

\author{
${ }^{1}$ Program Studi Pendidikan Dokter Fakultas Kedokteran Universitas Sam Ratulangi Manado \\ ${ }^{2}$ Bagian Anatomi-Histologi Universitas Sam Ratulangi Manado \\ Email: pelumingkewas@yahoo.co.id
}

\begin{abstract}
Psychotic disorder is a mental disorder characterized by hallucinations, delusions, catatonic behavior, chaotic behavior, chaotic speaking and are generally accompanied by poor performance. Spirituality is a belief related to the Almighty and the Creator. Current neuroscience approaches have touched the spiritual dimension, well-known as spiritual neuroscience. This term is used to describe human spirituality in terms of health and medicine perspectives. People with advanced spiritual personality are often regarded as those who have mental illness by the people around them. This study was aimed to determine the difference between psychotic symptoms and spiritual experience in the perspective of neuroscience. This was a descriptive study with a retrospective approach. We used research articles in journals pertaining to psychotic symptoms, spiritual experiences, and neuroscience, in addition searching for indicators that could help to differentiate the psychotic symptoms and spiritual experiences using a systematic review technique. Conclusion: There is a difference in brain activity between people who had spiritual experiences and those with psychotic symptoms.
\end{abstract}

Keywords: neuroscience, spiritual, psychotic

\begin{abstract}
Abstrak: Gangguan psikotik adalah gangguan jiwa yang ditandai dengan adanya halusinasi, waham, perilaku kataton, perilaku kacau, pembicaraan kacau yang pada umumnya disertai tilikan yang buruk. Spiritualitas merupakan keyakinan yang berkaitan dengan Yang Maha Kuasa dan Maha Pencipta. Saat ini pendekatan neurosains telah menyentuh dimensi spiritual, yang lebih dikenal dengan istilah neurosains spiritual. Istilah ini dipakai untuk menjelaskan spiritualitas manusia dipandang dari sisi perspektif kesehatan dan kedokteran. Orang dengan kepribadian spiritual yang maju sering dianggap memiliki penyakit mental oleh orang-orang di sekitarnya. Penelitian ini bertujuan untuk mengetahui perbedaan antara gejala psikotik dengan pengalaman spiritual dalam perspektif neurosains. Jenis penelitian ialah deskriptif retrospektif dengan cara mempelajari penelitian-penelitian yang telah dimuat dalam jurnal-jurnal yang membahas tentang gejala psikotik, pengalaman spiritual, dan neurosains serta mencari indikator yang dapat membedakan, dengan teknik telaah sistematik. Simpulan: Terdapat perbedaan aktivitas otak pada orang yang sementara mengalami pengalaman spiritual dengan orang yang mengalami gejala psikotik.
\end{abstract}

Kata kunci: neurosains, spiritual, psikotik

Gangguan psikotik adalah gangguan jiwa yang ditandai dengan adanya halusinasi, waham, perilaku kataton, perilaku kacau, pembicaraan kacau yang pada umumnya disertai tilikan yang buruk. Waham atau delusi adalah kepercayaan yang salah, berdasarkan simpulan yang salah tentang kenyataan eksternal, yang dipegang teguh meskipun apa yang diyakini semua orang merupakan bukti-bukti yang jelas dan tak 
terbantahkan., ${ }^{1,2}$

Spiritualitas merupakan keyakinan yang berkaitan dengan Yang Maha Kuasa dan Maha Pencipta. Menurut American Center for the Integration of Spiritually Transformative Experience (ACISTE), pengalaman spiritual sama dengan kesucian, noetic, di luar pengertian dan pengalaman manusia biasa, transpersonal, mistik, keagamaan dan pengalaman kegembiraan yang luar biasa. Hal ini menyebabkan seseorang melihat diri mereka dan dunia secara sangat berbeda dengan memperluas identitas mereka, menambah kepekaan mereka, dan mengubah nilai, prioritas, dan penghargaan mereka terhadap tujuan hidup. ${ }^{3}$

Neurosains merupakan bidang ilmu yang secara khusus mempelajari tentang sel-sel saraf atau neuron. ${ }^{4}$ Ilmu ini mempelajari segala sesuatu tentang otak manusia, mengkaji unsur-unsur biologiknya, serta mempelajari proses hubungan manusia dengan Tuhan. ${ }^{4,5}$ Saat ini pendekatan neurosains telah menyentuh dimensi spiritual, yang lebih dikenal dengan istilah neurosains spiritual. Istilah ini dipakai untuk menjelaskan spiritualitas manusia dipandang dari sisi perspektif kesehatan dan kedokteran. ${ }^{6}$

Orang dengan kepribadian spiritual yang maju sering dianggap sebagai orang yang memiliki penyakit mental oleh orangorang disekitar mereka. Contohnya ialah Swami Rama, guru spiritual Himalaya yang terkenal, menulis dalam biografinya bahwa dia sering terbangun di malam hari karena penglihatan tentang guru spiritualnya. Hal ini mengganggu orang tuanya dan mereka menganggapnya sebagai masalah kesehatan mental. Mereka berkonsultasi dengan banyak dokter, pendeta, dan astrolog tapi masalahnya tidak tuntas dengan terapi apapun. Contoh yang serupa di mana pengalaman spiritual tampak sangat mirip dengan gejala psikopatologi, juga ditemukan pada agama dan tradisi lainnya. ${ }^{7}$

Berdasarkan data-data di atas ditemukan kesulitan untuk membedakan gejala psikotik dan pengalaman spiritual. Penelitian ini bertujuan untuk mencari indikator yang dapat membedakan gejala psikotik dengan pengalaman spiritual dalam perspektif neurosains.

\section{METODE PENELITIAN}

Jenis penelitian ini ialah deskriptif melalui pendekatan retrospektif dengan cara mempelajari penelitian-penelitian yang telah dimuat dalam jurnal yang membahas tentang gejala psikotik, pengalaman spiritual dan neurosains dan mencari indikator yang dapat membedakan dengan teknik telaah sistematik.

Sampel dalam penelitian ini ialah jurnal-jurnal dari www.pubmed.gov dengan kata kunci spiritual experiences, psychotic symptom dan neuroimaging yang dipublikasikan dari tahun 2010 sampai 2017 dan yang bukan merupakan review article.

\section{HASIL PENELITIAN DAN BAHASAN}

Dari penelitian yang dilakukan sejak bulan Agustus 2017 - November 2017, penulis mencari artikel di Pubmed dengan kata kunci spiritual experiences dan neuroimaging dan mendapatkan 12 artikel. Setelah disaring sesuai dengan kriteria sampel maka artikel yang memenuhi syarat ialah satu artikel. Selanjutnya penulis mencari dengan kata kunci psychotic symptom dan neuroimaging dan hasil yang didapatkan ialah 142 artikel. Setelah di saring sesuai dengan kriteria sampel maka artikel yang memenuhi syarat ialah 19 artikel. Setelah itu penulis mencari datadata yang dapat dijadikan indikator untuk membedakan gejala psikotik dengan pengalaman spiritual dan didapatkan bahwa aktivitas otak pada orang yang sedang mengalami pengalaman spiritual dibandingkan dengan aktivitas otak saat istirahat menunjukkan peningkatan aktivitas dari bilateral occipital pole, left middle temporal gyrus, temporal pole, middle frontal gyrus, frontal orbital cortex left lateral occipital cortex, dan posterior cingulate gyrus. $^{8}$

Menurut penelitian yang dilakukan oleh Samel et al. ${ }^{9}$ pada tokoh-tokoh agama kristen GMIST (pendeta) di Resort Tahuna didapatkan bahwa terdapat hubungan 
bermakna antara kinerja otak dan spiritualitas, dalam hal ini terdapat pada pengalaman spiritual dan ganglia basalis yang diukur dengan menggunakan ISHA pada tokoh-tokoh agama kristen GMIST (pendeta) di Tahuna. Dari hasil penelitian penulis tidak disebutkan bahwa terjadi peningkatan aktivitas dari ganglia basalis; hal ini mungkin disebabkan karena kurangnya sampel jurnal yang membahas tentang pencitraan otak pada orang yang sedang mengalami pengalaman spiritual.

Untuk orang dengan gejala psikotik didapatkan bahwa terjadi peningkatan aktivitas pada bilateral dorsolateral prefrontal cortex, left amygdala, left middle frontal gyrus, bilateral frontal gyri, left precuneus, dan right pallidum. ${ }^{10-13}$ Juga terjadi penurunan aktivasi dari amygdala dan left precuneus, penurunan hubungan antara bilateral Heschl's gyrus seeds dengan dorsal anterior cingulate cortex dan antara hypothalamic dengan subgenual cortex. ${ }^{11-14}$ Selanjutnya didapatkan bahwa terjadi abnormalitas pada fungsi precuneus, aktivasi abnormal dari amygdala, midbrain, dan ventral striatum, juga terjadi abnormalitas dari white matter di right superior frontal gyrus, left middle frontal gyrus, bilateral parahippocampal gyrus, adjacent to the right caudate head, right thalamus, left insula, left lentiform nucleus, left fusiform gyrus, bilateral posterior cingulate, left anterior cingulate, right cingulate gyrus, left lingual gyrus, dan bilateral claustrum. ${ }^{15-19}$ Selanjutnya juga di dapatkan bahwa terjadi penurunan volume grey matter di right superior temporal gyrus, penurunan aktivasi di executive control circuitry yang berhubungan dengan defisit kognitif, terjadi penurunan volume seluruh brain gray matter dan perluasan dari volume white matter. ${ }^{11,18,20-22}$ Didapatkan juga bahwa terjadi penurunan volum yang nyata dari gray matter di lobus temporal medial serta korteks frontal, temporal, dan parietal. $^{23}$ Didapatkan juga bahwa efisiensi nodal dari amigdala, hippocampus, dan area otak frontotemporal-parietal memengaruhi gejala kegembiraan, kognitif, positif, dan negatif. ${ }^{24}$ Selanjutnya didapatkan juga bahwa terjadi disregulasi sistem kortikostriatal yang meluas ditandai paling menonjol oleh gradien dorsal ke ventral hipokonektivitas ke hiperkonektivitas antara daerah striatal dan prefrontal. $^{25}$ Didapatkan juga bahwa girus cingulatus (sebagai bagian dari sistem kortikal garis tengah) bersama dengan daerah hemisfer kanan mungkin terlibat dalam gejala selfappraisal pada psikosis onset awal. ${ }^{26}$

Pada penelitian yang membahas tentang otak dari pikiran yang menyimpang sebagai model otak dari skizofrenia didapatkan bahwa pikiran yang menyimpang berbanding terbalik dengan tingkat konektivitas di korteks prefrontal ventrikel kanan, wilayah otak yang terlibat dalam pengalaman diri di skizofrenia. ${ }^{27}$ Yang terakhir pada pasien dewasa muda dengan skizofrenia ditemukan bahwa integritas dari tract-based (kortikokortikal) dapat berada dalam batas normal. ${ }^{28}$

Dari hasil penelitian didapatkan bahwa saat seseorang mengalami pengalaman spiritual maupun saat seseorang mengalami gejala psikotik terdapat beberapa bagian otak yang mengalami peningkatan aktivitas. Pertama, yaitu kortex prefrontalis yang bertanggung jawab dalam membentuk kepribadian manusia. Di tempat ini perencanaan, motivasi, social judgement, mood, moralitas, rasionalitas, dan kesadaran manusia terutama diatur. ${ }^{29}$ Dari hasil penelitian didapatkan bahwa terjadi peningkatan aktivitas di korteks prefrontalis pada orang yang mengalami gejala psikotik. Untuk orang yang mengalami pengalaman spiritual belum ditemukan peningkatan aktivitas pada korteks prefrontalis. Kedua, ialah sistim limbik yang terdiri dari sejumlah struktur antara lain hippocampus, amygdala, dan gyrus cingulatus yang berfungsi dalam pengaturan emosi manusia, serta hipotalamus yang berfungsi antara lain dalam pengaturan suhu tubuh, tekanan darah, dan pernafasan. $^{29}$ Dari hasil penelitian didapatkan bahwa terjadi peningkatan aktivitas di amygdala kiri pada orang yang mengalami gejala psikotik dan terjadi peningkatan 
aktivitas pada gyrus cingulatus pada orang yang mengalami pengalaman spiritual. Amygdala terletak di interior di sisi bawah lobus temporalis yang sangat penting untuk memroses masukan yang menghasilkan sensasi takut. ${ }^{30}$ Lobus temporalis bertanggung jawab dalam proses memori, kegiatan berbahasa, persepsi penciuman, penglihatan, serta yang tak kalah penting berperan dalam persepsi suara dan bunyi. ${ }^{21}$ Dari hasil penelitian didapatkan bahwa terjadi peningkatan aktivitas dari lobus temporalis pada orang yang mengalami pengalaman spiritual dan tidak ditemukan peningkatan aktivitas pada orang yang mengalami gejala psikotik. Selanjutnya pada lobus oksipitalis yang terletak di posterior (di belakang kepala), yang melaksanakan pemrosesan awal masukan penglihatan. ${ }^{30}$ Dari hasil penelitian didapatkan bahwa terjadi peningkatan aktivitas dari lobus oksipitalis pada orang mengalami pengalaman spiritual dan tidak ditemukan peningkatan pada orang yang mengalami gejala psikotik. Yang berikutnya ialah lobus frontalis yang berperan dalam tiga fungsi utama: (1) aktivitas motorik volunter, (2) kemampuan berbicara, dan (3) elaborasi pikiran. $^{30}$ Dari hasil penelitian didapatkan bahwa terjadi peningkatan aktivitas di lobus frontalis pada orang yang mengalami pengalaman spiritual maupun pada orang yang mengalami gejala psikotik.

\section{SIMPULAN}

Dari hasil penelitian dapat disimpulkan bahwa terdapat perbedaan aktivitas otak pada orang yang sedang mengalami pengalaman spiritual dengan yang mengalami gejala psikotik yaitu terjadi peningkatan aktivitas pada gyrus cingulatus, lobus temporalis dan lobus oksipitalis pada orang yang sedang mengalami pengalaman spiritual sedangkan pada orang yang mengalami gejala psikotik terjadi peningkatan aktivitas pada cortex prefrontalis dan amygdala.

\section{SARAN}

Oleh karena kurangnya sampel jurnal yang meneliti tentang neuroimaging pada orang yang sedang mengalami pengalaman spiritual maka diharapkan adanya penelitian lanjuttentang neuroimaging pada orang yang sedang mengalami pengalaman spiritual agar dapat dijadikan acuan yang spesifik tentang indikator untuk membedakan pengalaman spiritual dengan gejala psikotik.

\section{DAFTAR PUSTAKA}

1. Fakultas Kedokteran Universitas Indonesia. Buku Ajar Psikatri (2nd ed). Sylvia DE, Gitayanti H, editor. Jakarta: Badan Penerbit FKUI, 2013; p. 79.

2. Sylvia M, Laurence B, Carine B, Brandt PY, Christiane G, Philippe H. Delusions with religious content in patients with psychosis. Psychiatry. 2010;73(2):158.

3. Bruce GMD. Differentiating spiritual and psychotic experiences. Journal of NearDeath Studies. 2014;32(3):124.

4. Pasiak T. Manajemen Kecerdasan: Memberdayakan IQ/EQ/SQ untuk Kesuksesan Hidup. Bandung: Mizan, 2006.

5. Wattimena R. Memperkenalkan status neurosains [cited 2012 Oct 15]. Available from: http://www.wima. ac.id/index.php? r=university/ article\& id $=1057$.

6. Dadana JC, Pasiak T, Wangko S. Hubungan kinerja otak dengan spiritualitas manusia diukur dengan menggunakan Indonesia spiritual health assesment pada pemimpin agama di Kota Tomohon. eBm. 2013;1(2):831.

7. Hemant B, Aarti J, Nagarathna R, Srinivasan TM, Bangalore NG. Schizophrenia Patient or Spiritually Advanced Personality? A qualitative Case Analysis. Springer Science. 2015;54(5).

8. Alessandra GM, Julio FPP, Alexander MoA, Klaus M, Ute H, Nils K. Neural correlates of psychotic-like experiences during spiritual-trance state. Psychiatry Research:

Neuroimaging. 2017;266:101.

9. Samel MD, Pasiak T, Ticoalu SHR. Hubungan kinerja otak dengan spiritualitas manusia diukur dengan menggunakan Indonesia Spiritual Health Assesment pada Tokoh-tokoh Agama Kristen GMIST (Pendeta) di Resort Tahuna. eBm, 2014;2(1). 
10. Smee C, Krabbendam L, O_Daly O, Prins A-M, Nalesnik N, Morley $L$ et al. An fMRI study of prefrontal dysfunction and symptomatic recovery in schizophrenia. Acta Psychiatr Scand. 2011;123(6):440.

11. Tsung-Wei Su, Tun-Wei Hsu, Yi-Ching Lin, Ching-Po Lin. Schizophrenia Symptoms and Brain Network Efficiency: a Resting-State fMRI Study. Psychiatry Research: Neuroimaging. 2015;234(2):209

12. Youngwoo BY, Je-Yeon Y, Wi HJ, Kang Ik K. Cho, Sung NK, Tae YL et al. Altered Fronto-Temporal Functional Connectivity in Individuals at UltraHigh-Risk of Developing Psychosis. PLoS ONE). 2015;10(8).

13. Amy EP, Peiying L, Hanzhang L, Michael K, Claire S, Carol T. Amygdala Hyperactivity at Rest in Paranoid Individuals With Schizophrenia. Am J Psychiatry. 2015;172(8):784.

14. Keith S, Jennifer K, Rowena G, Lakshika T, Allan R, Amy G et al. Decreased Hypothalamic Functional Connectivity with Subgenual Cortex in Psychotic Major Depression. Neuropsychopharmacol. 2015;40(04):849.

15. Rikandi E, Pamilo S, Mäntylä T, Suvisaari J, Kieseppä T, Hari R et al. Precuneus functioning differentiates first-episode psychosis patients during the fantasy movie Alice in Wonderland. Psychological Medicine. 2017;47(3): 495

16. Lee DY, Smith GN, Su W, Horner WG, MacEwan GW, Lapointe JS. et al. White matter tract abnormalities in first-episode psychosis. Schizophrenia Res. 2012;141(1):29.

17. Antoniusa D, Prudenta V, Rebanib Y, D'Angelod D, Ardekania BA, Malaspinaa D et al. White Matter Integrity and Lack of Insight in Schizophrenia and Schizoaffective Disorder. Schizophr Res. 2011;128(13):76.

18. Tanga J, Liaoa Y, Zhoub B, Tanb C, Liua T, Haoa $W$ et al. Abnormal anterior cingulum integrity in first episode, early-onset schizophrenia: A diffusion tensor imaging study. Brain Res. 2010;1343:199.

19. Romaniuk L, Honey GD, King JR,
Whalley HC, McIntosh AM, Levita L et al. Midbrain activation during pavlovian conditioning and delusional symptoms in schizophrenia. Arch Gen Psychiatry. 2010;67(12):1246.

20. Yue Y, Kong L, Wang J, Li C, Tan L, Su H et al. Regional Abnormality of Grey Matter in Schizophrenia. Plos One. 2016;11(1).

21. Francis MM, Hummer TA, Vohs JL, Yung MG, Liffick E, F. Mehdiyoun NF et al. Functional Neuroimaging Abnormalities in Psychosis Spectrum Youth. Brain Imaging Behav. 2016;10(1).

22. Palaniyappan L, Liddle PF. Diagnostic Discontinuity in Psychosis: A Combined Study of Cortical Gyrification and Functional Connectivity. Schizophrenia Bull. 2014;40(3):675.

23. Wolf DH, Satterthwaite TD, Calkins ME, Ruparel K, Elliott MA, Hopson RD et al. Structural Brain Abnormalities in Youth with Psychosis-Spectrum Symptoms. JAMA Psychiatry. 2015;73(5):515.

24. Nelson BD, Bjorkquist OA, Olsen EK, Herbener ES. Schizophrenia symptom and functional correlates of anterior cingulate cortex activation to emotion stimuli: An fMRI investigation. Psychiatry Research: Neuroimaging. 2015;234(3):285.

25. Fornito A, Harrison BJ, Goodby E, Dean A, Ooi C, Pradeep JN et al. Functional Dysconnectivity of Corticostriatal Circuitry as a Risk Phenotype for Psychosis. JAMA Psychiatry. 2013;70(11):1143

26. Morgan KD, Dazzan P, Morgan C, Lappin J, Hutchinson G, Suckling J. Insight, grey matter and cognitive function in first-onset psychosis. The British Journal of Psychiatry. 2010;197(2): 141.

27. Da-Jung Shin, Tae Young Lee, Wi Hoon Jung, Sung Nyun Kim, Joon Hwan Jang, Jun Soo Kwon. Away from home: the brain of the wandering mind as a model for schizophrenia. Schizophrenia Res. 2015;165(1):83.

28. Boosn HB, Mandl CW, vanHaren NE, Cahn W, vanBaal GC, Kahn RS et al. Tract-based diffusion tensor 
Lumingkewas, Pasiak, Ticoalu: Indikator yang membedakan gejala psikotik ...

imaging in patients with schizophrenia and their non-psychotic siblings. European Neuropsychopharmacol. 2013;23(4):295.

29. Dalili FA, Pasiak T, Wangko S. Hubungan Kinerja Otak dengan Spiritualitas
Manusia Diukur dengan Menggunakan Indonesia Spiritual Health Assesment pada Dosen STAIN. eBm. 2013;1(1): 271

30. Sherwood L. Fisiologi Manusia (8th ed). Jakarta: EGC, 2015; p. 157, 168. 